\title{
Coaching From A Philosophy Of Science Perspective
}

\author{
Thomas M. Krapu \\ St Louis, USA
}

\begin{abstract}
Coaching is a multidisciplinary human development method. As such there is no academic discipline that 'owns' the coaching profession. Having contributors from across disciplines can appear to result in an amalgam or patchwork of techniques that have been thrown together with no underlying principles to guide them. This can invite a view of coaching as nothing more than a utilitarian set of tools to accomplish discrete, individual goals. The purpose of this paper is to describe and discuss underlying principles to the coaching process that are rooted in the historical context of what coaching has been, is, and will be. These fundamental principles contain a specific view of personhood that has social and cultural implications that reach far beyond the practice of the coaching profession itself. Hence, there is a common claim that the coaching paradigm will and is changing the world. This article will attempt to substantiate this broad and sweeping claim by drawing on a philosophy of science perspective. The implications for a theory of coaching, the practice of professional coaching and the role of coaching research are also considered.
\end{abstract}

Keywords: philosophy of science, coaching, Thomas Kuhn, paradigm, core competencies, coaching theory

\section{Introduction}

The work of Brock (2014) has clearly demonstrated the multidisciplinary nature of the coaching profession. The significant contributors to the coaching profession come from all walks of life, and both academic as well as non-academic sources (Brock, 2014). This rich and diverse background is one of the strengths of the coaching profession. The diversity of sources of knowledge within coaching creates a situation where coaching is not beholden to any particular academic discipline, but benefits from many. This potentially removes any academic restraints on how coaching is viewed or theoretically conceptualized.

Of course the downside to this freedom comes in the form of the cost of academic credibility. Add to this the fact that most coach training programs 
have historically been free standing coaching schools, not academically housed, and the coaching profession can appear to lack credibility.

So the coaching profession has a couple strikes against it when it comes to being widely accepted as a credible human development practice. First, it is unregulated (Griffiths, 2008, p.19) and therefore lacks the credibility that government regulation gives other professions (e.g. psychology, counseling, medicine). Although it is worth noting that the International Coach Federation (ICF, 2011) has established itself as a self-governing body for the coaching profession.

Secondly, until 2002 it has been generally unacknowledged, unrecognized, or not even known within mainstream academia (Brock, 2014). The fact that the coaching profession in some measure has been unacknowledged or confirmed or even unknown within academia is not of great concern to many coaches who are simply doing the field work of coaching. Like a populist political movement, the coaching profession has sprung up from a groundswell of interest and the benefits people have experienced from coaching. Its training programs have generally not been rooted in academia and were created by an emerging set of leaders who invented and designed the core competencies and defined what coaching is and is not (Brock, 2014). Some of these core founders also helped create the International Coach Federation (ICF) as a professional body representing the coaching profession (Brock, 2014).

All this can lead to the perception that coaching is merely a fad or an amalgamation of specific techniques seeking simply to help people achieve goals in their life. While coaching does help people define and accomplish goals, it can do much more for individuals and teams, and it represents a much larger phenomenon within western culture and a shift for instance from a psychotherapy paradigm (world view) to a coaching paradigm. This paper will identify and describe the qualities underlying this movement and how a coaching culture is emerging through the growth of the coaching profession. This paper will take the position that the coaching profession is significantly pushing back on an existing psychotherapy culture we live in. In the language of Thomas Kuhn, the coaching profession may represent an anomaly that initially challenges a widely accepted psychotherapy paradigm and ultimately offers a new way of viewing human development. As in science, a new paradigm is something deeper than new evidence, a new paradigm represents a new way of seeing the world. 


\section{The psychotherapy culture}

The development of a psychotherapy culture is due to the emergence, increasing popularity, and significant impact that the fields of psychotherapy/psychology had on Western culture in general (Krapu, 2011). The use of the actual term psychotherapy culture goes back to at least 2001 (Yates, 2001). What is meant by a psychotherapy culture is that human behavior is most commonly viewed through a psychotherapy lens, which is rooted in a deficit based view of what it means to be human.

This psychotherapy culture we live in has resulted from the evolution of thinking in psychology in Western culture that began with the work of Freud (Krapu, 2011). Prior to Freud the explanation of human behavior was based on either a medical model (Degler, 1991) or a religious conception of what it means to be human (Hergenhahn \& Henley, 2013, p. 68). A common religious conception included a deficit view of human nature as expressed in the idea of original sin. In addition, historically, children were simply viewed as smaller versions of adults (Pollock, 1983, p. 48) and the thought of human development as we understand it today was virtually unrecognized.

Freud (1938) introduced the concept of psychological principles being at the heart of human behavior. He introduced a revolutionary idea (now commonly accepted) of how development was the root of adult psychological functioning. This represented a paradigm shift in thinking that was as significant in the history of science as Galileo's concept of the earth being round based on the shadow the earth casts on the moon or Copernicus' observation that the orbits of the planets were not perfect circles and the thought that the sun not the earth is the center of our solar system. Freud saw human life as based on internal psychological mechanisms that, in concert with the external environment, drove a preordained developmental process. This conceptualization transformed the conception of what it means to be human.

Since Freud's observations were based on pathology, his development model developed out of the need to explain pathological thought and behavior. What resulted was a model of human development based on a deficit model. Deficit models are based on developmental arrest or disruption rather than a theory of "normal" human development.

Freud's deficit model, then was based on the assumption that arrested development of some sort forms the basis of human development. 
Freud's theory of psychoanalysis took the world by storm and had a lasting effect on more than the science of psychiatry and psychology. His work influenced thinking in broad areas of culture from "literature, film, feminist and political theories" (Elliott \& Prager, 2016, p. 239). Freud's psychoanalytic model was at first an anomaly itself and not easily accepted, but became a cultural lens through which we began to see the world. A lens based on a deficit model of what it means to be human. This has evolved into a common cultural lens which I will call the psychotherapy culture.

The psychotherapy culture we live in is largely outside our direct awareness. Like other cultural lenses the psychotherapy culture is embedded in our experience. Consider commonly accepted terms like, repression, suppression, ego, superego, the unconscious and the "Freudian Slip" as well as phrases where we view people we know as being "nuts". If not for Freud, none of this would be possible. If lay people tend to think like a psychiatrist or clinical psychologist it is because we have embedded a deficit model into our cultural way of thinking.

The issue is not that there isn't truth reflected in our language, it is that this psychotherapeutic language within our culture is overgeneralized. Everything tends to be viewed through this lens.

This overgeneralization is also represented in the excessive use of psychological diagnoses. Consider when 15\% of children in school are diagnosed as having attention deficit disorder, an alarming rate even for ADD (Schwarz, 2013). Consider television shows that are named "Arrested Development", as well as indications that even severe diagnoses such as autism, attention deficit and childhood bipolar disorder may be overdiagnosed (Frances, 2010). Frances goes on to suggest that the new diagnostic manual for psychiatry (DSM-V) may invite an even larger group of potentially overdiagnosed conditions such as "hypersexuality, binge eating, mixed anxiety depression, minor neurocognitive, and others" (Frances, 2010, p. 1). This is further evidence that our thinking is shaped by a deficit model and often overgeneralized in its application. The overuse of diagnosis and their actual occurrence is a subject of debate. This debate itself represents a tension between the psychotherapy culture and the forces discussed in this article.

You can trace this overgeneralization of psychopathology all the way back to one of Freud's books, "The psychopathology of everyday life" (Freud, 1938). Here Freud normalized the analysis of daily life in terms of different 
fixated states that were rooted in a deficit model of psychology, a psychology of defense.

The reduction of thought and behavior to a theory of psychotherapy has embedded a deficit model into our fundamental thinking about what it means to be human.

Freud's theory of development suggests that "none of us get out alive", in that development is viewed as resulting in fixations that occur from the vicissitudes of life and affect everyone, since no one's development is perfect.

\section{Behaviorism: A response to psychoanalysis}

The first major challenge to Freud's thinking came with the emergence of the school of behaviorism within psychology. This reductive, science based empiricism that behaviorism represents can be viewed as an attempt to emulate the process of the natural sciences within psychology. It implemented a more experimental approach to researching human behavior and attempted to minimize or totally eliminate the role of that "unobservable" thing called "mind" as a part of the study (Rychlak, 1981, p. 389). This reduced the explanation of human experience to a causal and mechanistic view.

\section{The abundance mindset and emerging culture}

The "third wave" of psychology was represented by the rise of humanistic theories of human development and includes transpersonal theories (Brock, 2014). Humanistic theories were the answer to the problem of psychotherapeutic models becoming overgeneralized in how we look at human development and reductionistic in their effect in how we view human existence.

The rise of humanistic theories of what it means to be human represented a challenge to the status quo of deficit models.

One can view the coaching profession as an evolving cultural expression that challenges the universality of deficit models in particular and the psychotherapy culture in general, while offering an alternative view of normal adult human development. 


\section{The rise of positive psychology and the coaching mindset}

Positive psychology as represented by the work of Seligman (2006) represents a logical extension of humanistic theories of human development and is one contributor to the shift to a coaching mindset.

Seligman's strength based approach that focuses on one's purpose in life, the meaning we create in our lives and the importance of the fulfilment of a life design is a sharp contrast to a deficit model reliance on developmental arrest as the basis of human motivation.

The phrase "People are creative, resourceful and whole" is a common phrase in the coaching profession and expresses the cultural shift that began within the rise of humanistic theories. This phrase is so common within the coaching community it can sometimes be viewed as a slogan.

But this phrase is more than a slogan or a "bumper sticker" to be used in marketing coaching services. It represents a fundamental view of what it means to be human that challenges the deficit based, psychotherapy mindset that is embedded in our culture. So what does this phrase mean?

\section{Creative}

The views expressed within the coaching profession emphasize the fundamental creativity that humans possess. Creativity here is not viewed as a sublimation of internal conflict as classical psychoanalytic theory proposes. Here, creativity is an integral part of human potential that is additive and not just compensatory. This creative potential allows people to construct meaningful future states that don't exist in the present but are possible even though non-existent (see Rychlak on teleological causation, 1968).

\section{Resourceful}

The human potential movement claims that people by their very nature can access resources both within themselves and from their social and relational world that furthers their development and moves them toward specific ends in their life. (Rychlak, 1981)

Human resourcefulness is at the heart of the coaching profession's view that the client is equal to the coach and minimizes the power differential in the relationship. As I occasionally tell my coaching clients when they ask me for advice about their life, "You know yourself, your relationships and your 
world better than I ever will. How could I ever presume to have any advice about your life that was better than your own?"

Within humanistic theories, human development is not conceptualized in psychopathological terms and introduces the idea of coaching being rooted in "normal" human development. If development is "good enough" (Winnicott, 1992), rather than perfect, then for most people their development continues throughout their life without developmental arrest. For this reason, the field of adult development has had a strong influence on the coaching profession. Consider the work of Erik Erikson in his seminal book The Life Cycle Completed which was originally published in 1987 (Erikson \& Erikson, 1998). Erikson posited an entire lifespan that was represented by life challenges that were to be navigated, rather than developmental arrests that were to be overcome.

Or Gould's (1978) theory that posits four major false assumptions that people must overcome in order to move successfully from childhood to adulthood. For instance, it is common that adults from late twenties through the mid-thirties must overcome the assumption that, "Life is simple and controllable. There are no significant co-existing contradictory forces within me" (Gould, 1978, p.6).

\section{Wholenesd}

The concept of wholeness is implied by humanistic theories of development. An abundance view of development suggests that development most often occurs within normal limits, and it results in a person who is fundamentally intact, with a relatively stable personality and consistent view of themselves over time. They are simply human.

So rather than a bumper sticker, being referred to as "creative, resourceful and whole" is a basic claim about what it means to be human. This conceptualization changes everything if you have been seeing the world through the lens of a deficit model and within a psychotherapy culture.

Coaching is then both a world view as well as an applied methodology that applies humanistic developmental practices to help people develop and accomplish significant goals in their life that supports them to achieve their greatest potential. In fact, the coaching relationship can be transformative and help people become a person they experience as more completely themselves, in how they view themselves and how they exist in the world. 
This view of what it means to be human from the coaching perspective is often called the Coaching Mindset.

\section{The changing cultural shift implied by a coaching mindset}

The psychotherapy cultural mindset becomes a Procustrian bed when it views human development, where development tends to be forced into the constrains of a deficit model. Any problems or struggles in development are viewed within this model as fundamentally psychopathological and within the purview of psychotherapy. There is a resulting proclivity toward remediation rather than development.

Whether we, as coaches, view our clients as whole or not, what is important is how clients view themselves in relationship to us. Coaching creates the opportunity for clients to view themselves as whole and capable of designing and achieving a life of meaning and deep fulfillment. There is no reason to assume psychopathology or developmental arrest unless proven otherwise. Coaching proves that a deficit model is not necessary again and again with clients every day.

In ancient culture the Shaman was the one to go to, to make meaning out of life's mysteries. As a result of the psychotherapy culture the commonly accepted Shaman in modern culture has become the psychotherapist (think Dr. Phil). The coaching mindset is shifting our view of who the shaman is in our culture to coaches and other figures who are grounded in humanistic and positive psychology (think Tony Robbins).

\section{What it means to be human}

Coaching is a cultural forerunner in the change in the fundamental paradigm of how we, in Western culture, view what it means to be human.

This makes sense within the academic disciplines of humanistic and positive psychology, but within our general culture, the person on the street is not informed by humanistic or positive psychology. Often the person on the street is taught what to think about being human from the cultural viewpoint of the psychotherapeutic mindset that is still prominent in our culture.

This has profound implications on how coaching is viewed by the general public. The reason that coaches should be clear on the distinction 
between coaching and psychotherapy is so they can clearly communicate that distinction with their clients, who often rely on a psychotherapeutic or deficit model to understand themselves and human development.

\section{The practice of coaching}

The shift to a coaching mindset is a significant shift for students of coaching. As a result of the psychotherapy culture and their personal upbringing, it is not uncommon for coaching students to have a deeply held view of the world that is based on a deficit and scarcity world view. It is challenging for them to view their coaching clients as creative, resourceful and whole. This can tend to create a static relational position toward coaching clients that focuses on fixing, problem solving FOR the client, searching for what is wrong with the person or use of a predominantly problem-focused approach. Any of these artifacts can inhibit the coaching student from understanding and living core competencies of coaching (ICF, 2016) at the highest level. The shift to a coaching mindset for coaching students can itself be transformational.

\section{Changing the world}

The evolution of culture is ongoing. Beliefs that were once unquestioned go through a process of being challenged and changing over time. This has always been true and by all indications always will be.

Deficit models of what it means to be human, and the psychotherapeutic culture that has evolved since the work of Freud, evolved from a revolutionary and radical view of the world to a commonly accepted and deeply embedded world view.

Humanistic psychology challenges that scientific and cultural paradigm. The coaching profession is a way of viewing the world and an applied science that fundamentally applies the principles of humanistic psychology and its view of what it means to be human.

It is often said within the coaching profession that coaching is changing the world. On the face of it, this too sounds like a slogan or bumper sticker. But when you consider how widely accepted coaching is becoming and the broad name recognition the brand of coaching is attaining (ICF, 2012), one can see there might actually be something to this thing called coaching and how it is shaping our very view of the world. 
As more and more people accomplish significant things in their life as a result of coaching, and even transform their life in significant ways, coaching will be increasingly seen as a powerful methodology to effect change and growth in people's lives.

As coaching further develops as an evidence based applied science the more it will be seen as a validated methodology for human change.

But this will be more than a validation of a methodology. As is true in all science, this evidence base can be seen as a validation of the underlying theory, in this case about what it means to be human. Namely, that people are creative, resourceful and whole. And that coaching is indeed changing the world by replacing a deficit based paradigm with a strength and abundance based paradigm, the coaching mindset.

\section{Implications for coaching research}

Thomas Kuhn (2012) has illustrated the fact that when a scientific paradigm is being challenged it is more than a war of data but also, and even more so, a war of thoughts or ideas (theory). In fact, even an evidence based scientific approach is fundamentally based on ideas that are supported by facts. A common misconception about science is the idea that "the data speaks for itself". The truth is that ideas (theory) guide the researcher to decide what data is chosen in the first place. Theory determines which data is worth collecting and analyzing. This naturally raises the question of what those ideas are that are at the heart of coaching. Being creative, resourceful and whole is at the heart of how coaching views what it means to be human.

As Kuhn points out, even the normal process of an evidence based science is both theoretical and experimental (Kuhn, p. 33). Theory dictates what we examine scientifically, and empirical findings validate a theoretical perspective.

Existing research (Stewart, Palmer, Wilkin \& Kerrin, 2008) and meta analyses (Theeboom, Beersma \& van Vianen, 2014) have validated the practice of coaching. Stewart, et al validated positive outcomes in the areas of both intra-personal development and personal and performance as a result of coaching. While Theeboom et al. validated coaching's positive impact on performance/skills, well-being, coping, work attitudes, and goal-directed selfregulation. 
Future research in coaching needs to focus explicitly on demonstrating the impact of viewing people as creative, resourceful and whole. This could be done to validate some of the underlying humanistic assumptions within the coaching profession.

\section{Summary}

The philosophy of science can provide perspective on the evolution and future of the coaching profession, as well as its impact on the world. The history of coaching is short by comparison to other professions, but it is evolving within the larger historical context of the psychotherapy paradigm that is embedded in our culture. While initially challenging the psychotherapy paradigm the coaching paradigm offers a new way of viewing human development.

Frances (2010) states, "It is too bad that there is no advocacy group for normality that could effectively push back against all the forces aligned to expand the reach of mental disorders" (p. 3). But perhaps the coaching profession can be such an advocacy group. If the coaching mindset takes root culturally, then psychopathology will be reserved for those who truly warrant it and it will not be imposed upon the masses. People will look to coaching to reach their greatest potential.

Furthermore, the broader impact that the coaching profession might have is in relation to the transformation of our culture. Imagine a world where being creative, resourceful and whole is the default position for how people view being human.

\section{Acknowledgement}

The author thanks Julian Humphreys, anonymous reviewers, and Vicky Brock for their helpful comments concerning an earlier draft of this paper.

\section{References}

Brock, V. G. (2014). Sourcebook of coaching bistory (2 ${ }^{\text {nd }}$ ed.). Ventura, CA: Vikki Brock.

Degler, C. N. (1991). In search of buman nature: The decline and revival of Darwinism in American social thought. New York, NY: Oxford University Press. 
Elliott, A. 7 Prager, J. (2016). The Routledge bandbook of psychoanalysis in the social sciences and humanities. New York, NY: Routledge.

Erikson, E. H. \& Erikson, J. M. (1998). The life cycle completed. New York, NY: W. W. Norton \& Company.

Frances, A. (2010). Normality is an endangered species: Psychiatric fads and overdiagnosis. Psychiatric Times. July 06, 2010. Retrieved from http://www.psychiatrictimes.com/blogs/dsm-5/normality-endangeredspecies-psychiatric-fads-and-overdiagnosis.

Freud, S. (1938). The basic writings of Sigmund Freud. New York, NY: Random House, Inc.

Gould, R. (1978). Transformations: Growth and change in adult life. New York, NY: Simon \& Schuster.

Griffiths, K. (2008). Regulating the regulators: Paving the way for international, evidence based coaching standards. International Journal of Evidence Based Coaching and Mentoring, 6(1)

Hergenhahn, B. R., Henley, T. (2013). An introduction to the bistory of psychology 7thedition. Belmont, CA: Wadsworth Publishing.

ICF. (2016). Core competencies. International Coach Federation. Lexington, KY. Accessed on August 24, 2016 at http://coachfederation.org/credential/landing.cfm? Item Number $=2206$ \&navItemNumber $=576$

ICF. (2011). Coaching moves to self-regulate, International Coach Federation. Lexington, KY. Retrieved from http://coachfederation.org/prdetail.cfm? ItemNumber $=1906$

ICF (2012). ICF global coaching study, International Coach Federation. Lexington, KY. Retrieved from http://www.coachfederation.org/coachingstudy 2012

Krapu, T. M. (2011). The difference in coaching and psychotherapy and what you need to know. Denver, CO: Denver Coach Federation.

Kuhn, T. (2012). The structure of scientific revolutions: 50 th anniversary edition, Chicago, IL: University of Chicago Press; Fourth Edition. http://dx.doi.org/10.7208/chicago/9780226458144.001.0001

Pollock, L. A. (1983). Forgotten children: Parent-child relations from 1500 to 1900. Cambridge, England: Cambridge University Press.

Rychlak, J. F. (1968). A philosophy of science for personality theory. Boston, MA: Houghton Mifflin Co. http://dx.doi.org/10.1037/10535-000

Rychlak, J. F. (1981) Introduction to personality and psychotherapy: A theory construction approach (2nd ed.). London, England: Houghton Mifflin Co. 
Schwarz, A. (2013). The selling of attention deficit disorder. The New York Times, December 14, 2013. Retrieved from http://www.nytimes.com/2013/12/15/health/the-selling-of-attentiondeficit-disorder.html

Seligman, M. E. (2006). Learned optimism: How to change your mind and your life. New York, NY: Vintage.

Stewart, L., Palmer, S., Wilkin H. \& Kerrin, M. (2008). Towards a model of coaching transfer: Operationalising coaching success and the facilitators and barriers to transfer. International Coaching Psychology Review, 3(2).

Theeboom, T., Beersma, B. and van Vianen, A. (2014) Does coaching work? A meta-analysis on the effects of coaching on individual level outcomes in an organizational context. The Journal of Positive Poychology, 9(1). http://dx.doi.org/10.1080/17439760.2013.837499

Winnicott, D. W. (1992) The child, the family and the outside World (2 $\left.{ }^{\text {nd }} \mathrm{ed}.\right)$. New York, NY: Perseus Publishing.

Yates, C. (2001) Teaching psychoanalytic studies: Towards a new culture of learning in higher education. Psychoanalytic Studies 3(3-4) 333-347. http://dx.doi.org/10.1080/14608950120103631 